\title{
Caramel dye IV increases hepatic and renal oxidative stress injuries
}

Emerson Marins ${ }^{1}$, Julia Spanhol da Silva ${ }^{2}$, Aline Zuanazzi Pasinato ${ }^{1}$, Pâmela Carvalho da Rosa ${ }^{2}$, Vitor Antunes de Oliveira ${ }^{2}$, Joana Grandó Moretto $^{3}$, José Eduardo Vargas ${ }^{1}$, Felix Alexandre Antunes Soares ${ }^{2}$ and Rômulo Pillon Barcelos ${ }^{1-3 *}$

${ }^{1}$ Instituto de Ciências Biológicas, Universidade de Passo Fundo (UPF), Passo Fundo, RS, Brazil

${ }^{2}$ Programa de Pós-Graduação em Ciências Biológicas: Bioquímica Toxicológica, Centro de Ciências Naturais e Exatas (CCNE), Universidade Federal de Santa Maria (UFSM), Santa Maria, RS, Brazil

${ }^{3}$ Programa de Pós-graduação em Bioexperimentação, Universidade de Passo Fundo, Passo Fundo, RS, Brazil

\begin{abstract}
Caramel dye IV (C-IV) is a synthetic organic product, does not present nutritional, ergogenic, or technological factors, but leads to reactive oxygen species (ROS). This way may lead to damage to a wide range of molecules, leading to cancer, cardiovascular, and neurodegenerative diseases development. We aimed to verify the effects of different doses of C-IV dye on the markers of oxidative stress in the liver and kidneys from male Swiss CF-1 mice, divided into four experimental groups: control; C-IV $0.3 \mathrm{~g} / \mathrm{kg}$; C-IV $1 \mathrm{~g} / \mathrm{kg}$ and C-IV $3 \mathrm{~g} / \mathrm{kg}$. We found that mainly $3 \mathrm{~g} / \mathrm{Kg}$ of C-IV dye promote oxidative damage in liver and kidney homogenates, evidenced by the increase of lipid peroxidation, reduction of free $\mathrm{SH}$ groups, and higher ROS production. As a consequence, increased superoxide dismutase, catalase, and acetylcholinesterase enzyme activities were detected, as a response to the increased oxidative stress production. These damages were confirmed through histology images. Since the mice dose used in this study is 30-fold lower than the human daily dose consumption, these results indicate that the daily doses might induce substantial oxidative stress damages and possibly lead to chronic disease development.
\end{abstract}

\section{Introduction}

Dyes are usual ingredients used in food products and generally do not have nutritional, ergogenic, or technological importance for consumers, is used for food aesthetic purpose [1]. Among the dyes allowed as a food additive, (C-IV) has a special place among dyes as being the oldest and the most commonly used by the food industry in a wide range of foods [2], and is classified as a synthetic organic product [3].

This additive is produced through the sulfite-ammonia process; some acids and alkalis may also be added during its production [4], as sulfuric or citric acid, phosphoric, acetic and/or carbonic acid; alkalines such as hydroxides or mixtures of sodium, potassium and/ or calcium; and salts such as carbonate, hydrogen carbonate, sulfate and ammonium, phosphate sodium, potassium or calcium. Some ammonium compounds, such as carbonate and ammonium hydrogen carbonate, may also be added [5]. In this process, an ammonia interaction leads to sugar reduction, and byproducts such as 4-methyl imidazole (4-MEI) generation, which might presents highly toxic effects, such as neurological and cancerous pathologies [6] which lead, for example, the State of California to classify ut as a "cancer-causing chemical" [5]. According to the Expert Committee on Food Additives (JECFA) determined an Acceptable Daily Intake (IDA) of $300 \mathrm{mg} / \mathrm{kg}$ p.c. of Caramel IV dye [5].

A toxic intake can develop signs and symptoms that reveal an imbalance produced by the interaction of the poisonous agent with the organism [7]. Such imbalance can occur due to free radicals overproduction, that leads a pathological process named oxidative stress if that exceeds the antioxidant defenses [8]. Oxidative stress causes damage to a wide range of molecules including lipids, proteins, and nucleic acids that might lead to the development of diseases such as cancer, cardiovascular and neurodegenerative diseases [9].

Therefore, an investigation of possible toxic effects of C-IV dye has great importance, since it is included in a lot of food and drinks and, this way, consumed daily worldwide, mainly due to the lack of knowledge of the exact mechanisms responsible for its harmful effects and toxicity. Thus, this work aims to verify the effects of different doses of Caramel IV dye on the markers of oxidative stress in the liver and kidney of mice.

\section{Materials and methods}

\section{Animals}

Thirty-six male Swiss CF-1 male mice (30-40 g) g were obtained from our own breeding colony and kept in plastic boxes containing a maximum of five animals per cage under controlled environment conditions (12:12 h light-dark cycle, with the onset of light phase at $7: 00,25 \pm 1^{\circ} \mathrm{C}, 55 \%$ relative humidity) with standard food and water ad libitum. Mice were acclimated for seven days before initiation of any procedures. All experiments were conducted following national and international legislation: Brazilian College of Animal Experimentation

${ }^{\star}$ Correspondence to: Rômulo Pillon Barcelos, Programa de Pós-graduação em Medicina Veterinária: bioexperimentação, Instituto de Ciências Biológicas, Universidade de Passo Fundo (UPF), 99052-900 - BR 285, São José, Passo Fundo - RS, Brazil, E-mail: romulopillon@upf.br

Key words: liver, kidney, oxidative stress, caramel IV dye, toxicology

Received: April 17, 2020; Accepted: May 15, 2020; Published: May 18, 2020 
(COBEA) and the US Public Health Service's Policy on Human Care and Use of Laboratory Animals-PHS Policy and with the approval of the local Ethics Committee (\#013/2017).

The animals were randomly assigned into four groups and submitted to single and individual saline administration or Caramel IV dye by intra-gastric tube and kept in cages with only water.

\section{Experimental protocol}

Caramel IV (C-IV) was purchased from Prime Foods São Paulo, Brazil (lot 120117C), dissolved in saline and administered via intragastric gavage (i.g). Animals were kept in a 12 hours fast, randomly divided into four groups - nine animals per group: (A) control saline; (B) C-IV $0.3 \mathrm{~g} / \mathrm{kg}$; (c) C-IV $1 \mathrm{~g} / \mathrm{kg}$; (d) C-IV $3 \mathrm{~g} / \mathrm{kg}$. These dosages were based on Recommended Dietary Allowance (RDA) $(300 \mathrm{mg} / \mathrm{kg}$ per day to humans) [10]. Thus, the highest dosage used in this study is equivalent to $3,000 \mathrm{mg} / \mathrm{kg} /$ day for the ingestion of Caramel IV dye, 10 fold higher than the RDA. To study the effects of C-IV the i.g. route of administration was chosen since it is the most commonly used way that this dye is consumed worldwide.

After 4 hours of administration of the different doses, the animals were anesthetized with ketamine and xylazine for getting and separation of plasma through cardiac puncture and after euthanized by cervical dislocation. The liver and kidneys were removed and separated immediately. The experimental design is illustrated in Figure 1.

\section{Oxidative stress markers}

Lipid peroxidation assay: Lipid peroxidation was estimated by quantifying thiobarbituric acid reactive substances (TBARS), measured at $532 \mathrm{~nm}$, using a standard curve of malondialdehyde (MDA) [11].

ROS production assay: ROS generation was determined spectrofluorimetrically in liver homogenate using $2^{\prime} 7^{\prime}$ dichlorodihydrofluorescein diacetate (H DCF-DA) (1 $\mathrm{mM})$ [12]. Oxidized dichlorofluorescein (DCF) was determined using a standard curve [13].

Non-protein thiol measurement (NPSH): To estimate GSH content, we determined spectrometrically the NPSH content, according to Ellman [14].(ELLMAN; LYSKO, 1979).

\section{Antioxidant defense enzymes}

Catalase activity (CAT) and superoxide dismutase activity (SOD): The activity of the CAT enzyme was determined according to the method proposed by Aebi [15]. The kinetic analysis of CAT was started after $\mathrm{H}_{2} \mathrm{O}_{2}$ addition, and the color reaction was measured at 240 nm.(AEBI, 1984).

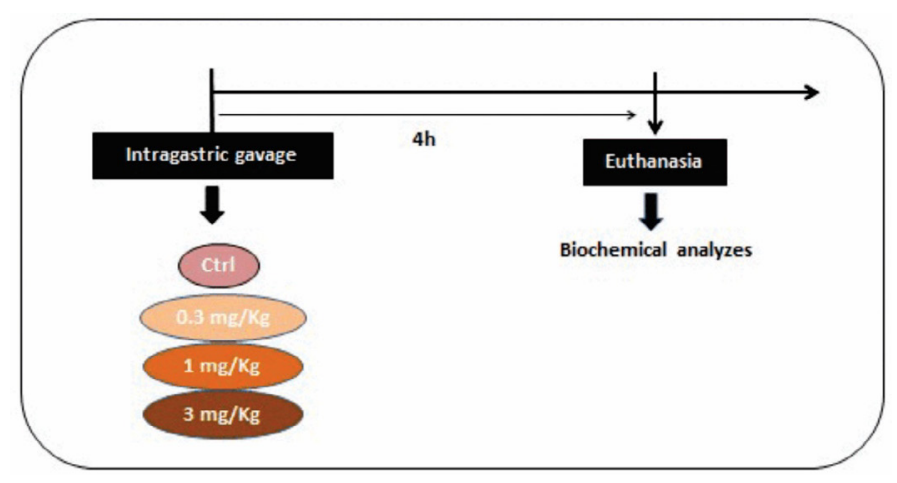

Figure 1. Description of the experimental protocol used in this study
Superoxide dismutase activity (SOD): The activity of the SOD enzyme was determined according to the method proposed by Misra and Fridovich [16]. The kinetic analysis of SOD was initiated after the addition of adrenaline, and the color reaction measured in a spectrophotometer at $480 \mathrm{~nm}$ [17].

Acetylcholinesterase: The AChE activity was estimated by the Ellman method [18] using acetylthiocholine iodide (ATC) as substrate and etopropazine as butyrylcholinesterase (BChE) inhibitor [19].

\section{Kidney and liver histopathological analyses}

After euthanasia liver and one kidney were rapidly extracted and fixed in $4 \%$ paraformaldehyde for 24 hours and then paraffin was embedded for histopathological and analyzed [20]. The samples were embedded in paraffin and sectioned using a microtome $(5 \mathrm{~mm}$ of section thick). For histopathological evaluation, alternate sections were deparaffined, rehydrated, and finally stained with hematoxylineosin according to standard procedures [21]. The sections were then observed with light microscopy at a final magnification of $400 \mathrm{x}$ (Olympus, Germany).

\section{Statistical analysis}

Statistical analysis was performed using the GraphPad Prism $6{ }^{\circ}$ program, with one-way analysis of variance (ANOVA), followed by Tukey post-test, $\mathrm{p}$ values $<0.05$ were considered significant.

\section{Results}

\section{Markers of oxidative damage}

Lipid peroxidation and ROS production: Figure $2 \mathrm{~A}$ indicates that groups C-IV $1 \mathrm{~g} / \mathrm{kg}$ and C-IV $3 \mathrm{~g} / \mathrm{kg}$ increased TBARS levels in the liver when compared to the control and C-IV $0.3 \mathrm{~g} / \mathrm{kg}$ groups ( $\mathrm{p}=0.0027$ ). In the kidney, C-IV $3 \mathrm{~g} / \mathrm{kg}$ increased TBARS levels compared to the control levels $((\mathrm{p}=0.0239)$.

Figure $2 \mathrm{~B}$ indicates an increased ROS production in C-IV $1 \mathrm{~g} / \mathrm{kg}$ and C-IV $3 \mathrm{~g} / \mathrm{kg}$ groups when compared to control levels ( $\mathrm{p}=0.0142$ ). Also, an increased ROS production was observed at C-IV $3 \mathrm{~g} / \mathrm{kg}$ group when compared to all other groups in the kidney $(\mathrm{p}=0.0049)$.

Non-protein thiol measurement (NPSH): Figure 3 indicates that no changes were observed between groups on the liver. However, a reduced NPSH level was found in the C-IV $3 \mathrm{~g} / \mathrm{kg}$ group when compared to the C-IV $1 \mathrm{~g} / \mathrm{kg}$ group on the kidney of mice $(\mathrm{p}=0.0279)$.

\section{Antioxidant defense enzymes}

Figure $4 \mathrm{~A}$ shows that an increased activity of CAT was observed in the hepatic tissue at C-IV $3 \mathrm{~g} / \mathrm{kg}$ group when compared to control and $0,3 \mathrm{~g} / \mathrm{kg}$ groups $(\mathrm{p}=0.0189$ ). In addition, increased CAT activity was found on the kidney at C-IV $3 \mathrm{~g} / \mathrm{kg}$ group when compared to the other groups $(\mathrm{p}=0.0267)$.

Figure 4B shows an increased liver SOD activity in the C-IV $3 \mathrm{~g} / \mathrm{kg}$ group when compared to control and $0,3 \mathrm{~g} / \mathrm{kg}$ groups $(\mathrm{p}=0.0054)$ and increased activity at kidney $(\mathrm{p}=0.0294)$ for the C-IV $3 \mathrm{~g} / \mathrm{kg}$ group when compared to control.

Figure 4C shows that all C-IV doses induced an increase in AChE activity when compared to the control of the liver $(\mathrm{p}<0.0001)$. On kidney, C-IV $3 \mathrm{~g} / \mathrm{kg}$ group increased AChE activity in comparison to group control and $0,3 \mathrm{~g} / \mathrm{kg}$ groups $(\mathrm{p}<0.0057)$. 
A)
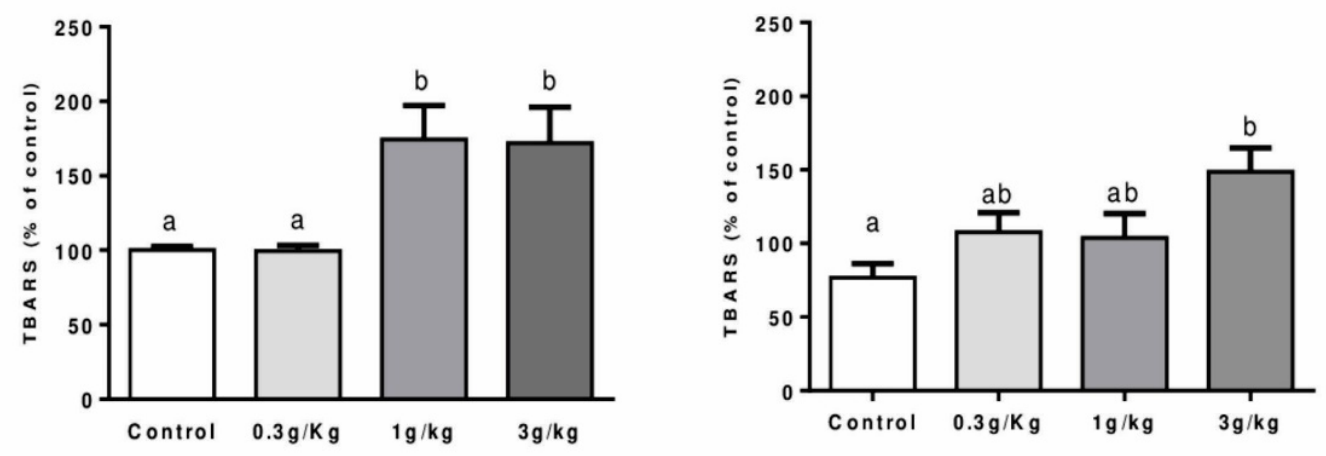

B)
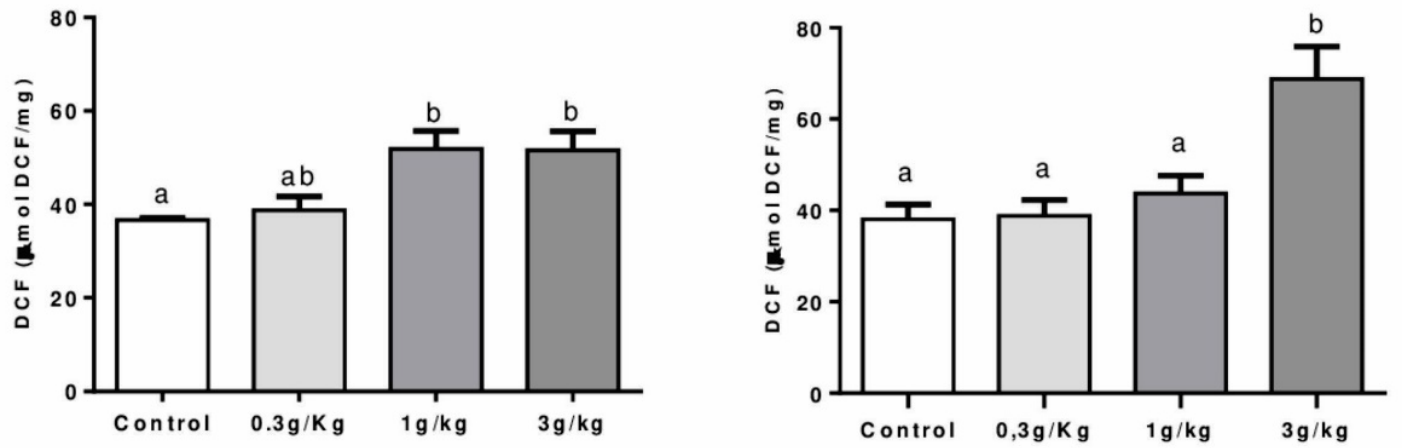

Figure 2. Effect of Caramel IV on lipid peroxidation (TBARS levels) (A) and ROS production (B) in the liver (left column) and kidney (right column) of mice. Data are expressed as mean \pm S.E.M $(n=9, p<0.05)$. Means for a variable with superscripts without a common letter differ
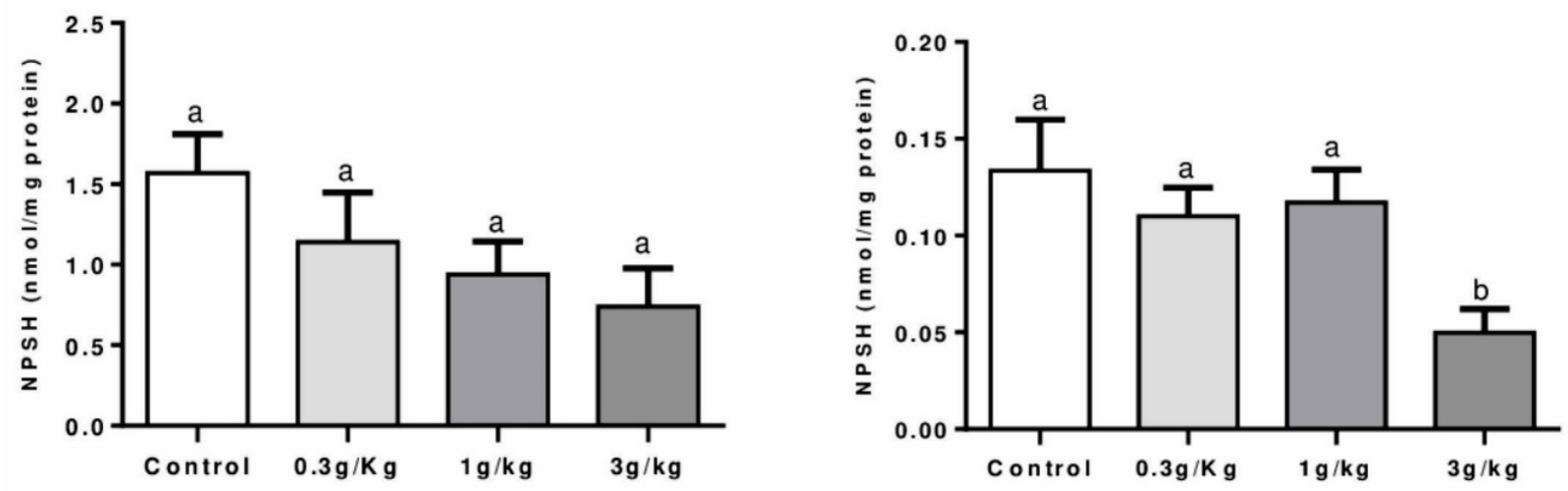

Figure 3. Effect of Caramel IV on NPSH levels in the liver (left column) and kidney (right column) of mice. Data are expressed as mean \pm S.E.M ( $\mathrm{n}=9$, $\mathrm{p}<0.05$ ). Means for a variable with superscripts without a common letter differ

\section{Histological analysis}

No histopathological changes (Figure 5) were observed in control, $0.3 \mathrm{~g} / \mathrm{kg}$, and $1 \mathrm{~g} / \mathrm{kg} \mathrm{C}$-IV groups in both liver (panels A, B, and C, respectively) and kidney (panels E, F, and G, respectively). However, panel D shows the C-IV $3 \mathrm{~g} / \mathrm{kg}$ group induced a diffuse mild paracentral hydropic degeneration at the liver. Similarly, panel $\mathrm{H}$ demonstrate the presence of glomerulonephritis and moderate multifocal proliferative membrane and low glomerulus count caused by C-IV $3 \mathrm{~g} / \mathrm{kg}$ administration.

\section{Discussion}

In this study, we demonstrated that C-IV $1 \mathrm{~g} / \mathrm{kg}$ and $3 \mathrm{~g} / \mathrm{kg}$ promoted the development of oxidative stress damages in mice tissues, represented by increased hepatic lipid peroxidation, reduction of NPSH groups and increased production of reactive species and histological alterations in both liver and kidney. Besides, we demonstrated that C-IV is responsible for activating the antioxidant defense system, represented by the increased activity of the enzymes catalase, superoxide dismutase and acetylcholinesterase on mice liver and kidney. 
A)
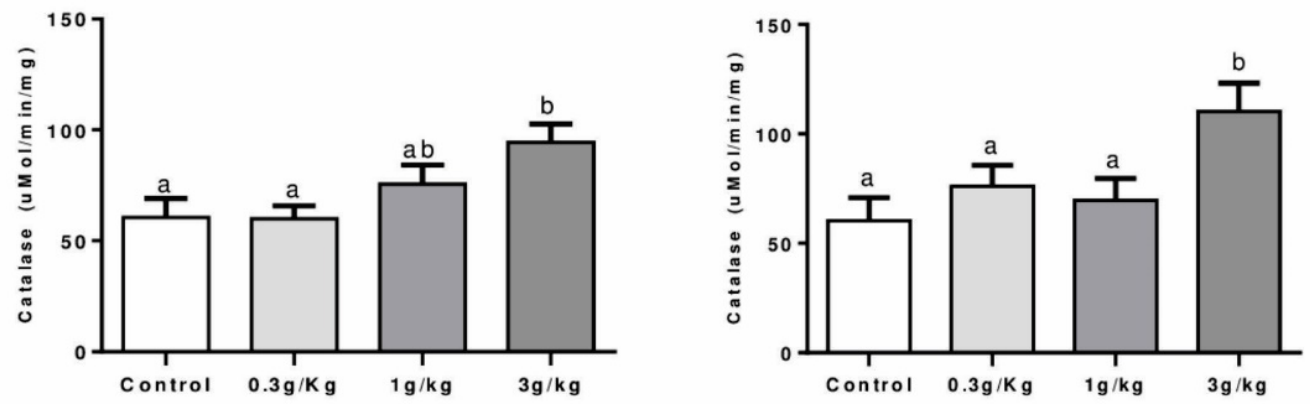

B)
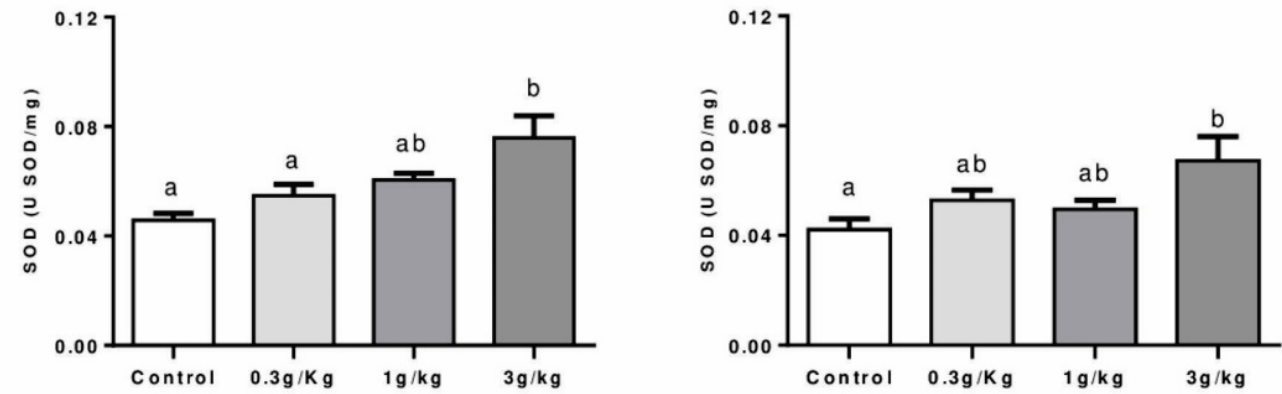

C)
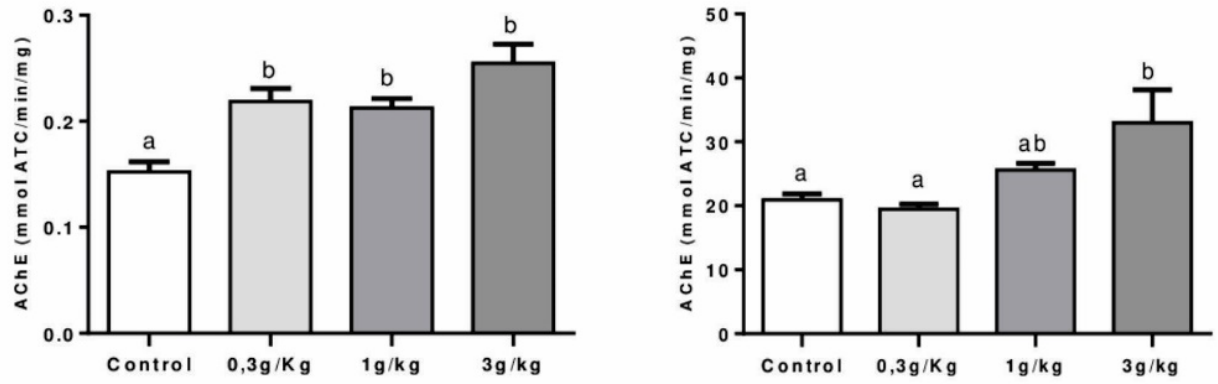

Figure 4. Effect of Caramel IV on the activity of the antioxidant enzymes: CAT (A), SOD (B), and AChE (C) in the liver (left column) and kidney (right column) of mice. Data are expressed as mean $\pm \operatorname{SEM}(\mathrm{n}=9, \mathrm{p}<0.05)$. Means for a variable with superscripts without a common letter differ

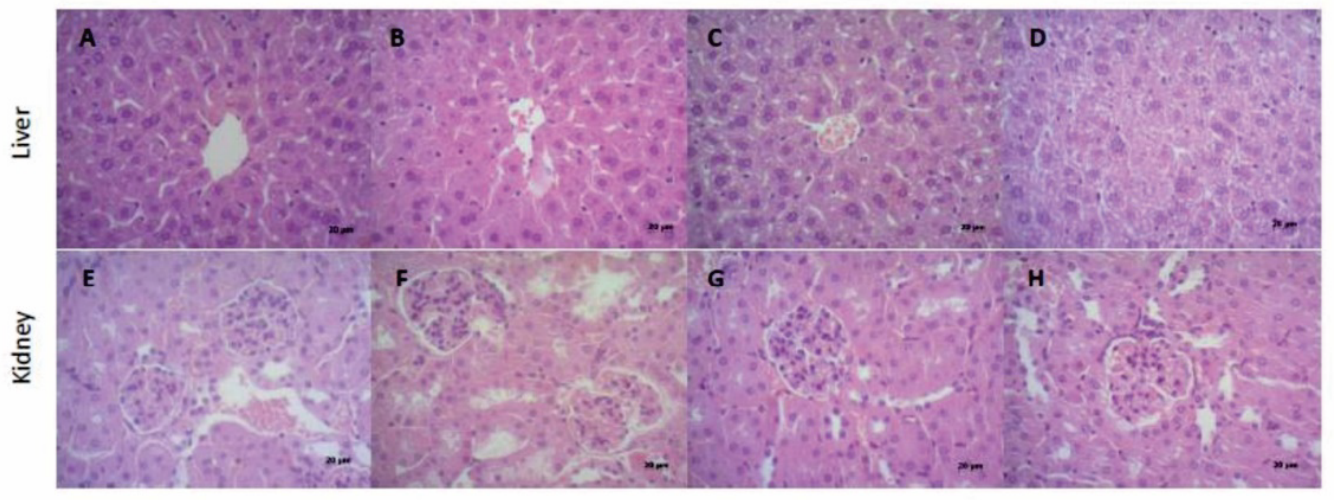

Figure 5. Photomicrographs (final magnification of 400x) in the liver (panels A-D) and kidney (panels E-H) of mice by HE. Liver and kidney section of mice in control (panels A and E), $0.3 \mathrm{~g} / \mathrm{kg}$ (panels B and F), and $1 \mathrm{~g} / \mathrm{kg}$ (panels C and G), C-IV showed normal structure of hepatocytes and glomerulus and renal tubules respectively. C-IV $3 \mathrm{~g} / \mathrm{kg}$ (panel D) shows a diffuse mild paracentral hydropic degeneration at the liver. Kidney sections in C-IV $3 \mathrm{~g} / \mathrm{kg}$ group (panel $\mathrm{H}$ ), present glomerulonephritis and moderate multifocal proliferative membrane and low glomerulus count 
C-IV dye production process is characterized by the presence of nitrogen and sulfur in their manufacture chemical reactions, and its production leads to the high molecular weight constituents (HMW) formation (responsible for color differentiation) and low molecular weight constituents (LMW) formation (responsible for unintentional substances such as 4-methylimidazole (4-MEI)) [5]. The effects of oxidative damage after C-IV administration here may be associated with 4-MEI, also classified as a human carcinogen and the most potent neurotoxic substance by the International Agency for Research on Cancer [22].

In this sense, mice treated with 4-MEI at 100, 130, and $160 \mathrm{~g} /$ $\mathrm{kg}$ presented a higher percentage of chromosomal mutations after 12 hours and 24 hours after 4-MEI exposure, indicating that 4-MEI is genocytotoxic to mice [23]. Besides, studies evidenced increased neonatal mortality in rodents treated with C-IV, the formation of full moon neoplasms [6], tissue pigmentation alteration, and changes in body weight, in urine and hematological examinations [10].

The higher ROS production, especially hydrogen peroxide and superoxide, may be due to the mediation of cytochrome P450, which is recognized for promoting this increase [24] since 4-MEI has a structure very similar to 2 and 3-methylfuran which has the cytochrome P 450 protein after its metabolism [25]. Similarly, high doses of paracetamol following cytochrome P450 metabolism generates a toxic metabolite known as $\mathrm{N}$-acetyl-p-benzoquinoneimine, that can be conjugated with reduced glutathione and depleting its hepatic stores [26]. We suggest that the cytochrome P450 pathway may be activated at high doses of C-IV due to the presence of 4-MEI, which is structurally similar to 2 and 3-methylfuran and has cytochrome P450 metabolism. Collaborating with this hypothesis, we demonstrated here that higher doses of C-IV are highly toxic through increased hepatic lipid peroxidation and may damage cell membranes, altering their structure and permeability [27].

In addition, glycotoxins, or lipid peroxidation products, promote the formation of advanced glycation and products (AGEs) [28] through the Maillard reaction, a process that occurs during the caramel dye caramelization process [29]. C-IV is considered to be rich in AGEs, and their molecules are considered highly reactive, acting as donors of electrons for the generation of free radicals, which can promote the development of oxidative stress and consequent cellular damage [30]. AGEs activate specific receptors called RAGE (Receptor Advanced Glycation End-products) and produce inflammatory cytokines, such as interleukin 1 and 6 (IL-1 and IL-6), tumor necrosis factor-alpha (TNF- $\alpha$ ), protein C reactive (PCR). This AGE-RAGE interaction seems to mediate the generation of free radicals, altering the permeability and vitality of the cellular membranes [30], which corroborates with our results about the formation of oxidative markers and leading to oxidative stress [28-30].

The deleterious action of free radicals can be inhibited and/or reduced through the activation of the antioxidant defense system, maintaining the cellular homeostasis, preventing the amplification of the damages. According to our study, we demonstrated that C-IV was able to induce an increase in antioxidant enzyme defense system, represented by SOD, CAT, and acetylcholinesterase in the analyzed tissues [31]. This modulation on the antioxidant system modulation might be considered as a response to the increased ROS formation, but not sufficient to prevent or blunt the oxidative damages induced by C-IV administration.

This oxidative stress damage could be observed by histological analysis in both liver and kidney of mice caused by C-IV $3 \mathrm{~g} / \mathrm{kg}$ administration, where diffuse mild paracentral hydropic degeneration could be identified at the liver and possible glomerulonephritis, moderate multifocal proliferative membrane, low glomerulus count at kidney tissue. In addition, studies show that animals treated with 2-methylimidazole develop renal lesions consisting of hemosiderin, which is most evident in male mice [25]. These alterations are linked to increased hepatic lipid peroxidation and renal ROS damages.

This way, we point out that this is a critical study, since if we use a dosage conversion factor between human $\mathrm{x}$ mice - a method that applies an exponent for body surface area, which account for the difference in metabolic rate, to convert doses between animals and humans the highest dose use here is about to 30 fold lower than the RDA for humans [32]. This way, it highlights the relevance of our study, since low doses, even those below RDA, are causing many tissues damages and oxidative stress development.

Finally, it is known that AGEs production might lead to an inflammatory process [30], so, there is a high possibility that C-IV might lead to an inflammatory process, by increasing cytokines and triggering specific inflammation receptors [30]. This hypothesis will be investigated in future studies from our group.

\section{Conclusion}

Our study showed for the first time that high dose of Caramel Dye IV promotes oxidative stress at mice's liver and kidneys, demonstrated by increased levels of TBARS, ROS production, and NPSH reduction, given the potential cytotoxic effect of the same, since it possesses in its composition the substance 4-MEI, already being recognized for its harmful effects through possible routes of oxidation and metabolization. Besides, C-IV can promote a change in the redox system, observed by increased renal and hepatic activities of CAT, SOD, and AChE. Since the mice dose used in this study is 30 -fold lower than the human daily dose consumption, these results indicate that the daily doses might induce substantial oxidative stress damages and possibly lead to chronic disease development. Further studies are needed to understand the mechanisms that $\mathrm{CI}-\mathrm{V}$ induces the oxidative and possible inflammation damages to cells.

\section{Acknowledgments and funding}

The work was supported by the PRONEM/CNPq/FAPERGS 16/25510000248-7 and CAPES/PROEX 23038.005848/2018-31 research grants. FAAS received a fellowship from CNPQ. JSS and PCR received a fellowship from CAPES.

\section{Conflict of interest statement}

The authors declare no conflict of interest.

\section{References}

1. Prado MA, Godoy HT (2003) Corantes artificiais em alimentos. Alim Nutr.

2. Cunha SC, Barrado AI, Faria MA, Fernandes JO (2011) Assessment of 4-(5-) methylimidazole in soft drinks and dark beer. J Food Compos Anal.

3. Scientific opinion on safety of steviol glycosides for proposed uses as a food additive. EFSA J.

4. Sengar G, Sharma HK (2012) Food caramels: A review. J Food Sci Technol 51: 16861696.

5. Vollmuth TA (2018) Caramel color safety - An update. Food Chem Toxicol 111: 578596.

6. NT Program (2007) Toxicology and carcinogenesis studies of 4-methylimidazole (Cas No. 822-36-6) in F344/N rats and B6C3F1 mice (feed studies). Natl Toxicol Program Tech Rep Ser. 
7. Buschinelli JT (2011) Manual para interpretação de informações sobre substâncias químicas.

8. Seddon M, Looi YH, Shah AM (2007) Oxidative stress and redox signalling in cardiac hypertrophy and heart failure. Heart 93: 903-907.

9. Stohs SJ (1995) The role of free radicals in toxicity and disease. J Basic Clin Physiol Pharmacol 6: 205-228.

10. MacKenzie KM, Boysen BG, Field WE, Petsel SRW, Chappel CI, et al. (1992) Toxicity and carcinogenicity studies of Caramel Colour IV in F344 rats and B6C3F1mice. Food Chem Toxicol 30: 431-443.

11. Ohkawa H, Ohishi N, Yagi K (1979) Assay for lipid peroxides in animal tissues by thiobarbituric acid reaction. Anal Biochem.

12. Myhre O, Andersen JM, Aarnes H, Fonnum F (2003) Evaluation of the probes $2^{\prime}, 7^{\prime}$-dichlorofluorescin diacetate, luminol, and lucigenin as indicators of reactive species formation. Biochem Pharmacol.

13. Pérez-Severiano F, Rodríguez-Pérez M, Pedraza-Chaverrí J, Maldonado PD, MedinaCampos ON, et al. (2004) Santamaría, S-Allylcysteine, a garlic-derived antioxidant, ameliorates quinolinic acid-induced neurotoxicity and oxidative damage in rats. Neurochem Int.

14. Ellman GL (1959) Tissue sulfhydryl groups. Arch Biochem Biophys 82: 70-77.

15. Aebi H (1984) Catalase in vitro. Methods Enzymol 105: 121-126.

16. Misra HP, Fridovich I (1972) The role of superoxide anion in the autoxidation of epinephrine and a simple assay for superoxide dismutase. J Biol Chem 247: 3170-3175.

17. Bradford MM (1976) A rapid and sensitive method for the quantitation of microgram quantities of protein utilizing the principle of protein-dye binding. Anal Biochem.

18. Ellman GL, Courtney KD, Andres V, Feather-Stone RM (1961) A new and rapid colorimetric determination of acetylcholinesterase activity. Biochem Pharmacol.

19. Worek F, Mast U, Kiderlen D, Diepold C, Eyer P (1999) Improved determination of acetylcholinesterase activity in human whole blood. Clin Chim Acta

20. Oliveira VA, Favero G, Stacchiotti A, Giugno L, Buffoli B, et al. (2017) Acute mercury exposition of virgin, pregnant, and lactating rats: Histopathological kidney and liver evaluations. Environ Toxicol 32: 1500-1512.
21. Stacchiotti A, Favero G, Giugno L, Lavazza A, Reiter RJ, et al. (2014) Mitochondrial and metabolic dysfunction in renal convoluted tubules of obese mice: protective role of melatonin. PLoS One 9: e111141.

22. Nishie K, Waiss AC, Keyl AC (1969) Toxicity of methylimidazoles. Toxicol Appl Pharmacol.

23. Norizadeh Tazehkand M, Topaktas M, Yilmaz MB, Hajipour O, Valipour E (2016) Delineating the antigenotoxic and anticytotoxic potentials of 4-methylimidazole against ethyl methanesulfonate toxicity in bone marrow cell of swiss albino mice. Bratislava Med J.

24. Du K, Ramachandran A, Jaeschke H (2016) Oxidative stress during acetaminophen hepatotoxicity: Sources, pathophysiological role and therapeutic potential. Redox Biol 10: $148-156$.

25. Chan PC, Hills GD, Kissling GE, Nyska A (2008) Toxicity and carcinogenicity studies of 4-methylimidazole in F344/N rats and B6C3F1 mice. Arch Toxicol 82: 45-53.

26. Colle D, Arantes LP, Gubert P, da Luz SCA, Athayde ML, et al. (2012) Antioxidant properties of taraxacum officinale leaf extract are involved in the protective effect against hepatoxicity induced by acetaminophen in mice. J Med Food 15: 549-556.

27. Mello Filho AC, Hoffmann ME, Meneghini R (2015) Cell killing and DNA damage by hydrogen peroxide are mediated by intracellular iron. Biochem $J$.

28. Odani H, Shinzato T, Usami J, Matsumoto Y, Frye EB, et al. (1998) Imidazolium crosslinks derived from reaction of lysine with glyoxal and methylglyoxal are increased in serum proteins of uremic patients: Evidence for increased oxidative stress in uremia. FEBS Lett 427: 381-385.

29. Nseir W, Nassar F, Assy N (2010) Soft drinks consumption and nonalcoholic fatty liver disease. World J Gastroenterol 16: 2579-2588.

30. Voyer LE (2019) Artículo especial reacción de maillard. Efectos patogénicos glicación endógena efectos patogénicos.

31. Barbosa KBF, Costa NMB, de CG Alfenas R, De Paula SO, Minim J (2010) Bressan, Estresse oxidativo: conceito, implicações e fatores modulatórios. Rev Nutr 23: 629-643.

32. Nair AB, Jacob S (2016) A simple practice guide for dose conversion between animals and human. $J$ Basic Clin Pharm.

Copyright: (C2020 Marins E. This is an open-access article distributed under the terms of the Creative Commons Attribution License, which permits unrestricted use, distribution, and reproduction in any medium, provided the original author and source are credited. 